\title{
Comparative study of community medicine practice in MBBS curriculum of health institutions of Nepal
}

\section{Marahatta SB 1 , Sinha NP ${ }^{2}$, Dixit $\mathbf{H}^{3}$, Shrestha IB $^{4}$, Pokharel PK}

${ }^{1}$ Assistant Professor, Department of Community Medicine, ${ }^{2}$ Professor, Department of Community Medicine, Kathmandu University School of Medical Sciences, Dhulikhel, Nepal, ${ }^{3}$ Professor, Department of Paediatrics, Kathmandu Medical College, Kathmandu Nepal, ${ }^{4}$ Professor, Community Medicine and Family Health, Institute of Medicine Tribhuvan University, Kathmandu, Nepal, ${ }^{5}$ Professor, Department of Community Medicine BPKIHS, Dharan Nepal Kathmandu Nepal

\begin{abstract}
Background: A revolution in health care is occurring as a result of changes in the practice of medicine and in society. Medical education, if it is to keep up with the times, needs to adapt to society's changing attitudes. Presently medical education has been criticised for its orientation and insensitivity to people's need. The MBBS curriculum of medical institutions of Nepal has been focusing on community-based approaches and is still guided by the same notion. The question put forward is whether it has been appropriate to nurture the present health needs and aspiration of people.

Objective: The objective of the present study is to review the existing community based medical education in health institutions of Nepal to strengthen the components of community care.

Materials and methods: Qualitative study was done by reviewing the curricula and existing community medicine courses/activities in MBBS curriculum of Institute of Medicine (IoM)/Tribhuvan University, BP Koirala Institute of Health Sciences (BPKHIS) and Kathmandu University School of Medical Sciences (KUSMS).

Findings and Discussion: The curriculum of all the health institutions have addressed significantly on community medicine practice. As per Institute of Medicine, the community medicine practice is achieved through community based learning experiences like community diagnosis, concurrent field with families of sick members and district health system management practice. In BP Koirala Institute of Health Sciences, community medicine practice is undertaken through exposure to community diagnosis program, health care delivery system, family health exercise, applied epidemiology and educational research methodology, management skills for health services and Community Oriented Compulsory Residential Rotatory Internship Program (COCRRIP). In KUSMS, community medicine module is carried out as- community diagnosis program, community health intervention project, school health project, occupational health project, health delivery system functioning, family health care activities and Compulsory Residential Rotatory Internship Program in outreach clinics. In the practice the practical aspects are largely unstructured that waste too much time in non-educational activities and rely on learning and doing. Meanwhile, expectation of the community is increasing and the challenge of nurturing their demands has come in forefront. Community has perceived that the medical schools are concentrating on fulfilling the demand of their curriculum rather directing on their health care need.

Conclusion: Health institutions need to be accountable to take the responsibility of strengthening the health status of the community of their catchments areas. The practice of community medicine need to be done in an innovative way and these schools should execute continual intervention activities and complement other institutions working in their areas.
\end{abstract}

Key words: Community medicine, curriculum, field practice

$\mathrm{B}$ omedical sciences and clinical medicine have achieved phenomenal advancement and successes during the past 50-60 years. The new and ever improving diagnostic, pharmacological and instrumental armamentaria have made physicians increasingly effective and powerful in combating diseases ${ }^{1}$. Advances in medical sciences and technology are but a part of these events. Since there is an organic relationship between medicine and human advancement, the evolution of medical education should be viewed against civilisation and advancement at that time ${ }^{2}$. There was noticeable development in medical education as the theory of disease causation changed from supernatural to germ causation and from genomics to proteomics. In this

\section{Correspondence}

Sujan B. Marahatta

Department of Community Medicine

Kathmandu University School of Medical Sciences

Dhulikhel, Kavre

E-mail: sujanmarahatta@gmail.com 
regard, medical education needs to be directed to aspire not only the teaching of diagnosis and management, the mainstay of medical education for the last hundred of years or more, but optimum health requires more than this. The role of medical education has been to produce professionals who can understand and assume their responsibilities to meet the wider health care need of their people to remain physically, mentally, socially and spiritually healthy as envisaged by WHO. Equally reassuring for the future of medicine is the continued evolution of medical education itself ${ }^{3}$.

Medical education should evolve based on science to serve patients. Despite the innovation in medical arena, the developing countries are lagging behind to reap the benefits. The importance of primary health care components in health care delivery system is still evident. Therefore, it has become necessary to incorporate ingredients of primary health care to reinforce the medical education. With the existing system, to facilitate the health care delivery approach, community care needs to be incorporated and practiced. Obviously, health science students need to be equipped with the essential knowledge and skills to address these issues. Community based medical education is the theme of medical education of Nepal. The current practices related to the community-centred education need to be analysed and strengthened to address the wider need of the community.

The purpose of the present study is to review the existing Community Based Medical Education in Health Institutions of Nepal to strengthen the components of community care.

\section{Materials and methods}

As the intent was to elicit and explore issues related to community based medical education, the authors selected a qualitative approach to compare the philosophy and existing community medicine courses of the MBBS programs of Institute of Medicine / Tribhuvan University, BP Koirala Institute of Health Sciences and Kathmandu University School of Medical Sciences. Basic information on the philosophy and contents of the community medicine was obtained from the MBBS curriculum of the respective institutions and the departments of the community medicine and from published documents.

\section{Findings}

\section{A. Philosophy and Concept of Community Based Medical Education in IOM/ Tribhuvan University}

The Institute of Medicine (IOM) was established in 1972 under Tribhuvan University and had the mandate and the responsibility of training all the categories of health manpower needed in the country.

In the beginning the stress was on training of middle level health workers. The programmes run for this purpose were ANM, CMA, and Proficiency Certificate Course in General Medicine, Pharmacy, Radiology, Physiotherapy, Nursing, Health Laboratory and Traditional Medicine.

With the passage of time, institutional goals of IOM have kept on changing. With the demand of time, institutional goals to IOM have been entrusted with a new responsibility of training the human resources for health of tertiary level health professionals. By 1977 it had at graduate level, a 2-year Bachelor of Nursing Programme in Community Nursing, Paediatric Nursing and Adult Nursing.

In 1978, a community-oriented integrated MBBS programmes was started with intake of 22 students. Later on it was made 30 and it was subsequently increased to 40. The current intake of MBBS students is 61 as per the annual report of 2009.

A three hundred-bedded TU Teaching Hospital was completed in 1984 with support from JICA and another 100 beds were added in 1993. Tribhuvan University Teaching Hospital is now an almost 800 bedded hospital. This hospital is being used for the teaching/ learning activities of different programmes run by IOM; it also carries out the research work.

At post-graduate level, a three year Postgraduate Generalist (Family Physician) Training in 1982 and oneyear Postgraduate Diploma in Anaesthesiology in 1984 were started with the support from the University of Calgary, Canada. Today the IOM is running 29 different programmes from proficiency certificate level to the highest postgraduate degree in medicine, public health, paramedical, nursing and traditional medicine (Ayurved Science) through 9 campuses scattered all over the country, Tribhuvan University Teaching Hospital, and various academic programmes in the near future. It also has 5 affiliated campuses.

The goals of IoM are:

- Production of human resources for health services, education and research

a Provide health services through its health institutions

- Conduct research in health sciences

MBBS program at the Institute of Medicine was conceived and started in response to the national health 
needs identified through district health surveys in rural districts (Tanahu, Bara, Nuwakot and Dhankuta) which were carried out to develop need-based curriculum. The survey results provided the basic data necessary for curriculum planning. The job description of medical officer was analysed. The curriculum was designed on the basis of the health needs and perceived relevance to the community, and the roles to be performed by the medical graduates to serve the health services in the districts of Nepal. Despite passage of time it has remained true to the ideals that motivated its establishment. In 1978 the program was conceived as Medical Science Diploma of Doctor of General and Community Medicine (MSDDGCM) ${ }^{4}$. It was later however termed a MBBS when the first batch qualified in 1984 .

This program is known for its strong community orientation and stress on integrated learning of basic science subjects. In addition, the strategies of promoting problem based self directed learning adopted by this institute helps our graduates to prove their abilities in different situation. However over the years there have been many comments on MBBS program of IOM. At the time when community based medical education was introduced in Institute of Medicine, it was viewed sceptically as producer of third grade graduates and barefoot doctors. Community based medical education has been viewed as not being based on science and for neglecting the importance of premedical courses. The graduates were blamed for not being competent in dealing with the patients as they spent most of their time in the community than in the hospital. Another handicap was not being recognised in other countries. The community-oriented physician, trained in a community oriented medical education system was referred to as a substandard species.

IoM had to face a lot of opposition to this type of thinking. With all the above resistance, IoM is the first medical institution in Nepal to introduce community orientation, systems approach, problem-based and integrated teaching.

Institute of Medicine has a mandate and responsibilities different from many other medical colleges, it being a public sector institution created with the government funds. The features of IoM are as follows: lower fees, highly competitive entrance examination yet still the most sought after medical school in Nepal, experienced and committed faculty members on permanent employment of the university, extensive clinical learning resources including in house internet server and well established library. Besides, Institute of Medicine functions almost as a health science university and conducts a large number of certificate, bachelor and postgraduate programmes in different discipline. Plans are underway to start a Public Health School.

\section{Community Medicine Practice Model}

Diagnosis of the state of the health of a community is as important for community medicine as clinical diagnosis is for the care of an individual patient. There is a need to ensure continuing surveillance of the population's health and evaluation of health care programs. To execute above mentioned task the knowledge of epidemiology, biostatistics, demography, sociology, environmental health, occupational health, nutrition, health financing, health related behaviour, health promotion and health administration is indispensable. Having fundamentals of these will enable them to identify the state of the health status of the community, the underlying factors responsible to precipitate the problem and existing health care system, their functional aspects, constraints and challenges. This will broaden their horizon and enable to think in broad spectrum of health.

Community based practices are essential components with the specific aim of developing the student's competencies in understanding community health problem and later to enable them to solve these problems working with the community. All field activities are need-responsive, problem solving, and community oriented, which encourages students to render services while they learn and develop clinical and public health management skills.
Important areas of Community Medicine
口 Community diagnosis
C Community health care
口 Surveillance of health
Evaluation of the programmes

Curriculum Outline and Implementation Modality

First Year Community Medicine and Integrated Basic Medical Science

Second Year Integrated Basic Medical Science

Third Year Applied Epidemiology, Family Health Exercise, Forensic Medicine, Clinical Subjects

Fourth Year Clinical subjects, District Health Service Management

Four and half Year Clinical Subjects Final (one year) Rotating Internship

Approaches to community based learning

a Taught courses mostly in 1st year with small components in the 2 nd and the 3 rd phases 
- The community orientation is achieved through community based learning experiences like community diagnosis, concurrent field with families of sick members and district health systems management field.

Community field programmes are the essential component of IoM with the specific aim of developing the student's competencies in understanding community problem and solving these by and through working with the community. All field activities are need-responsive, problem solving, and community oriented, which encourages students to render services while they learn and develop clinical and public health management skills.

\section{B. Philosophy and Concept of Community Based} Medical Education BPKIHS Perspectives

B.P Koirala Institute of Health Sciences (BPKIHS) established in 1993, upgraded to a deemed university in 1998, is an autonomous Health Sciences University with a mandate to work towards developing socially responsible and competent health workforce. Striving continuously to meet the health needs at the primary, a secondary and tertiary level is its primary responsibility. The medical education at BPKIHS started on October 19, 1994 with the intake of the first batch of MBBS students. Gradually it started B.Sc. Nursing in 1996, BDS, MD/ MS, M.Sc. and the CN Programme in 1999, OT and AS in 2000, BMIT in 2001 and B.Sc. MLT in 2005. At present altogether 908 students are studying various programmes. The number of students programme wise is: MD/MS 155, M.Sc. 18, MBBS 264, BDS 160, B.Sc. Nursing 54, B. Sc. MIT 18, Certificate Nursing 120, OT \& AS 17, B.Sc MLT 10, MBBS Interns 57 and BDS Interns 35. The Institute is started the MPH programme from September 2005. In order to provide students a community oriented medical education and to create a socially accountable health work force in the nation, this Institute has launched the concept of a 'Teaching District'. Presently Sunsari, Morang, Dhankuta, Saptari, Jhapa and Ilam districts are included, but gradually all the districts of the entire eastern region of Nepal (16 districts) will be included in teaching districts. In terms of achieving the educational goals of the Institute both the present curricula and future educational program are need based, integrated, community oriented and partially problem solving in the line with innovative medical education program epitomised in the Edinburgh Declaration of 1998.

\section{Mission of BPKIHS}

To improve the health status of the people of Nepal and the neighbouring regions by providing holistic health care through training of compassionate, caring, communicative and socially accountable health workforce acting as catalyst of change and through advancement in research and innovation in service as well as education to ensure healthy individuals and families by collaborating with all stakeholders.

\section{Community Medicine Practice Module}

Phase I (Multiprofessional exposure to Community diagnosis programme)

\section{Objectives}

口 To appreciate working atmosphere in team

ㄱo bridge the gap between the professionals

a To identify the current scenario of different system and fragmented care to comprehensive need of people.
Methodology
- Village leaders meeting
- Social mapping
口 House-to-house survey
口 Focus group discussion
a Health education
a Health exhibition
- Health camp
․ Report presentation

Phase I Second Year (Health Care Delivery System) Objectives

- To familiarise the students about Health Care Delivery System

- To understand the structure and functions of the different NGOs /INGOs working in Health

Methodology: Six-field visits

a Sub-health Posts with FCHVs

a Primary Health Centres

- Teaching District Health Units

- SOS Bal Gram, Itahari

- Purvanchal Anathasram

- Elderly Care Home, Mulghat

Phase II (Third year) Family Health Exercise

Objectives

- To analyse the social and cultural variables related to health and disease in the family

口 To enable the family care in health and diseases

- To work with school hygiene and sanitation of the area

\section{Methodology}

ㅁ Each Student- Family of five.

- Fifteen Visits: Once in 15 days 
- Each Visit: 4 Hours, and to present findings in Log Book

Phase II (Third year) Applied Epidemiology and Educational Research Methodology (EPIDMAN)

\section{Objectives}

* Appreciate the importance of designing a scientific study.

* List various epidemiological study designs.

* Carryout simple epidemiological study

* Report preparation and presentation

* Integrate learned knowledge \& skills by presenting accurately in presence of adjunct faculties of Health Professional Education Dept

Methodology

- Students-10 Groups

- Each group-Epidemiological Investigation of National Health Problems

Phase II (Fourth year) Management skills for health services (HEALTH MAN)

\section{Objectives}

- Understand the activities at all levels of health care system

- Appreciate the importance of managerial skills in health care delivery services

- Observe all activities of Zonal Hospital and District Public Health Office

- Familiarise with the mechanism of monitoring and supervision, including health financing

- Understand the Health Management Information System (HMIS)

\section{Methodology}

- Three Groups - Mechi, Koshi, Sagarmatha Zonal Hospitals

$$
\text { - District Public Health Office }
$$

Phase-II (Fifth to ninth semester) Learning in Field Objective

- To work up socio-clinical cases.

- To learn about the morbidity and mortality pattern at the level of primary health centre and district hospital

\section{Methodology}

- By visiting to the District Health Office, Sunsari, Sunday, Tuesday and Friday with Faculties of Medicine, Surgery, Paediatrics, Obs/Gyn, Orthopaedics, ophthalmology, ENT, Dermatology, Psychiatry and Community Medicine.
Phase-II (Fifth Year Internship Program) Community Oriented Compulsory Residential Rotatory Internship Program (COCRRIP)

Objective

- To give Preventive, Promotive and Curative Services.

- To take part in all the activities at Zonal \& District Hospitals

- To conduct Health Education Session and School Health Program.

- To learn Managerial Skills.

- To carry out a research project.

Methodology

- Six month posting at Teaching Hospital (BPKIHS)

- Six months at Zonal \& District Hospitals

- 15 days in District Public Health Office

- 15 days in Primary Health Centre

Total Field Posting for MBBS Course

Programs

Days

- Orientation Courses

- Multi-Professional Exposure in CDP 15

- Health Care Delivery System 6

- Family Health Exercise 15

- Learning in Field 84

- Applied Epidemiology \& ERM 45

- Planning for Health Management 15

- Internship

- Zonal \& District Hospitals 150

- District Public Health Office 15

- Primary Health Centre 15

Total (days)

C. Philosophy and Concept of Community Based Medical Education in KUSMS

Kathmandu University School of Medical Sciences (KUSMS) is a not-for-profit, non governmental medical college of Kathmandu University (KU). KUSMS was established in 2001 in joint collaboration with KU and Dhulikhel Hospital (DH).

Currently KUSMS offers the MBBS Program apart from other programs in health sciences. The KUSMS MBBS program is an autonomous program, established to produce technically competent, socially responsible and behaviourally compassionate medical graduates.

KUSMS Educational strategy is based on ProblemBased Learning (PBL) and Community-Based Learning 
(CBL). This is the first medical college in Nepal include PBL as an integrated part of the curriculum. PBL comprises small group tutorial sessions under the guidance of faculty tutor. Following this, self directed, independent learning takes place. This is supplemented by laboratory experiments and lectures on selected key topics. CBL comprises of Teaching/Learning in community with regular residential posting as well as the usual classroom learning.

\section{Community Medicine Practice Module}

\section{First Year}

Philosophy

To acquaint the students about the phenomenon and social aspects of health, disease and care

I) Community Diagnosis Program (CDP): 1 Month

II) Observational study

\section{Second Year}

Philosophy: To carry out intervention programs to reduce the health and disease burden in the community

Community Intervention Project focused on:

a Awareness on health and diseases

a Promotion of maternal and child health

․ Promotion of hygiene and sanitation/ Environmental Protection

- Uplift health care utilisation behaviour in community

\section{Third Year}

Philosophy: To carry out specific intervention programs to reduce the health and disease burden in the community

Specific Intervention Project focused on:

- School Health

- Occupational Health

․ Study of the health delivery system

\section{Fourth Year}

\section{Philosophy}

a To conduct comprehensive family health intervention in order to reduce the health and disease burden of the family

a To aware about the national/international health system and national priority health programs

Comprehensive Family Health Intervention focused on:

Clinico-social aspects

\section{Internship}

Philosophy

- To conduct comprehensive health care activities and to address the health problems at the individual, family and community level.

Community Medicine Posting

- 8 weeks in six different outreach centres- Dapcha, Bhaunipati, Boldhe, Baluwa and Dhading PHCs.

\section{Activities}

a Patient care

In the patient management at the health centre working closely with the residential paramedical staffs and the visiting doctors

a Managerial function

In all the activities of the health centre, e.g. record keeping, dispensing, communication with the hospital, managing logistics etc.

- Health education/promotion activities:

Counselling sessions to the patients in relation to different diseases.

Special counselling sessions to the patients in relation to family planning, $\mathrm{MCH}$

\section{Discussion}

The philosophy of community oriented medical education has been to acquaint the students about the phenomenon of the disease process and underlying factors and enable them to understand health problems of the community and acquire clinical/managerial skills to deal with the public health problems. Looking at the philosophy and practice of community based medical education of three institutions of Nepal; it appears that focus has been given since the beginning of the year till the end year. As per Institute of Medicine, the community medicine practice is achieved through community based learning experiences like community diagnosis, concurrent field with families of sick members and district health system management practice. In BP Koirala Institute of Health Sciences, community medicine practice is undertaken through exposure to community diagnosis program, health care delivery system, family health exercise, applied epidemiology and educational research methodology, management skills for health services and Community Oriented Compulsory Residential Rotatory Internship Program (COCRRIP). In KUSMS, community medicine module is carried out as- community diagnosis program, community health intervention project, school health project, occupational health project, health delivery system functioning, family health care activities and Compulsory Residential Rotatory Internship Program 
in outreach clinics. In the initial two years, students are trained to acquire fundamental understanding about the health and diseases. The community diagnosis exposure of each institution is focused to enable the student understand the factors that affect the health and wellbeing of the individual. It offers them practical understanding about the factors that trigger ill health and widen their thinking about the social, cultural, behavioural, economic and health system. It enables them to identify the state of the health status of the community, the underlying factors responsible to precipitate the problem and existing health care system, their functional aspects, constraints and challenges. This will broaden their horizon and enable them to think in broad spectrum of health.

After community diagnosis, exposure in third year, both IoM and BPKIHS offer family health exercise to enable the student to understand the health problems at family level and offer necessary interventions. However in KUSMS such exercises are conducted in fourth year. Prior to sending for family health practicum, the students gain practical exposures in school health, occupational health and health delivery system. As per the orientation of curriculum, BPKIHS has given strong focus on enabling students to conduct an epidemiological research to enhance their skills of designing scientific study and putting in practice. This seems an innovative endeavor. The curriculum of all the institutions has given emphasis in understanding health system of the country and its framework from grass root level to the national level. Thus community diagnosis, family health exercise, study of the health system of the country are the major areas of the practice in all institutions and in addition focus in research activities by BPKIHS and community placements during internships are major community based activities practiced by BPKIHS and KUSMS.

Community based practices are essential components with the specific aim of developing the student's competencies in understanding community health problem and later to enable them to solve these problems working with the community. Meanwhile, it is essential to enable them to be accountable towards the community and develop as socially accountable physicians. Looking back to the history of IoM, the oldest institution in Nepal, has this mission been achieved? Bearing in mind the fact that as we ourselves have grown up in community and have our first hand experiences there, so is it essential to have community exposure?

The usual state of affairs is that not more than $10 \%$ of patients visit the hospital and not more than $1 \%$ are admitted. Why do we then continue to limit our clinical teaching within the walls of the hospital and claim to be producing competent doctors? For these doctors to be competent it is vital that they receive a balanced training in all levels of health care: primary, secondary and tertiary as well as having familiarity with the culture, traditions and other psychosocial aspects of the families and communities within which they are to practice medicine. $^{5}$

Beside all this the practical aspects, being largely unstructured, waste too much time in non-educational activities and rely on learning and doing. Meanwhile, expectation of the community is increasing and the challenge of nurturing their demands has come in forefront. Community has perceived that the medical schools are concentrating on fulfilling the demand of their curriculum rather directing to the health care needs of the community with which they are involved. The communities have been used for the sake of academic pursuit rather than the other way round. Their awareness about they being used for academic pursuits has made them reluctant to act as learning tools for medical students. As a result the communities have been refractory towards external influences and have been reluctant to participate in such works. One of the reasons is that the urban and suburb communities who might not be an appropriate target for such purposes have been used by medical colleges for the sake of accessibility.

In fact, a large number of the existing communityoriented medical schools base a large proportion of their educational activities in the hospital but utilise ambulatory and out-patient departments as well as bedside teaching. We are not trying to minimise the role of bedside teaching, what we are saying is that it should not be the sole or major mode of clinical teaching, as it would then be irrelevant ${ }^{5}$.

Medical schools need to continually address on target areas with continual follow up of the work and focus on addressing health care needs along with the academic pursuit. Innovative health interventions need to be designed and applied as per the reality of the circumstances. Majority of community-oriented schools, in addition to trying to make their education relevant to community health needs, also try their best to make use of the science of education in their teaching/ learning strategies; this is by no means an easy task, and a great effort is put into it by both teachers and students. The aim is to improve and develop medical education. Therefore, it is illogical to view this in reverse and claim that it is done for the purpose of producing second- or third-grade doctors. ${ }^{5}$ 
To strengthen community based medical education medical institutions need to be accountable and must design innovative intervention strategy to address the health problems identified in the community ${ }^{6}$. This endeavour will motivate the community to participate in such activities. If communities and their active participation in decision-making and action for health is the essence of the new public health, then that must be the starting point for conceptualisation of content and orientation. People in communities and their resources and informed choices will be at the core of the health system, in relation to which all other elements need to be described and tested for relevance. Enabling communities to make the best choices for health, and providing them with necessary assistance in the protection against disease become the key tasks of public health. The challenge goes beyond the concern for relevance and the need to understand local values and constructions of health and disease in order to improve communication for better compliance. The notion of learning from the community confirms that the community actually has something to contribute. It reflects an attitude of basic respect for accumulated knowledge and trusts in that each individual and group of individuals have abilities, resources and creativity which are essential for health. ${ }^{7}$

One of the ideal approaches could be that the medical institutions taking direct accountability of health care of certain areas within their catchments and use the health facilities within those areas as teaching centres. Lack of clarity in functional domain of Ministry of Education and Ministry of Health and Population have been hindering the colleges in devising appropriate strategy to address the ethos of community based medical education.

\section{Conclusion and Recommendations}

1. Community based practices are essential components with the specific aim of developing the student's competencies in understanding community health problems. These later enable students to solve these problems whilst working with the community. All field activities need to be need-responsive, problem solving, and community oriented. This encourages students to render services while they learn and develop clinical and public health management skills.

2. There is no doubt in the context of Nepal that community based medical education can be an ideal endeavour but how it can be practiced in realistic way? The expectation of the community has increased in the changing context and they are refractory to external interferences. Challenges are multiplying. To provide truthful and effective community based medical education it is now the appropriate time to review our current practices and re-design as per the demand.

3. The means to involve the community actively and strengthen community health development endeavours in sustained way to benefit community is essential. This will facilitate in the health care developmental endeavour and enrich the medical institutions, community and boast the moral of community based institutions working in this field collectively.

4. Medical colleges need to be accountable to take the responsibility of strengthening the health status of the community of their catchments areas. The practice of community medicine needs to be done in an innovative way and the colleges should execute intervention activities continuously and complement other institutions working in their areas. To increase the health status of the community they need to facilitate and strengthen the governmental and nongovernmental institutions in their catchments areas. They also need to increase the capacity and utilise these as their training sites.

5. Medical schools need to continually address on target areas with continual follow up of the work and focus on addressing health care needs along with academic pursuit. The innovative health interventions need to be designed and applied as per the reality of the circumstance. In this regard, governmental institutions, INGOs/NGOs need to work together sharing the resources and translate the ethos of community based medical education in the real sense.

\section{References}

1. Solyom AE. Contemporary challenges of medical education: morality and integrity of physicians. [cited on 2009 Jan]. Available from: http://www.ishm2006.hu/scientific/abstract. php? ID=290.

2. Marahatta SB, Dixit H. Students' perception regarding medical education in Nepal. KUMJ. 2008; 6(2):273-83.

3. School of Medical Sciences, Kathmandu University. Report on Present Status of Medical Education in Nepal: Need for Twenty-First Century. Kathmandu: Kathmandu University; January 2006.

4. Mattock NM, Abeykoon P. Innovative program of Medical Education in South East Asia. Regional Publication SEARO. 1993; No 21:2940.

5. Hamad B. Community-oriented medical education: what is it? Med Edu. 1991; 25(1):1622. 
6. Marahatta SB. Community Based Medical Education: Where we are heading?. KUMJ. 2007;5(2):149-50.
7. Mogedal S. Learning from community; implication of new approach to public health for medical education. Med Edu.1994; 28:1269. 